\section{Brief psychotherapy in Alzheimer's disease}

\author{
Randomised controlled trial
}

\author{
ALISTAIR BURNS, ELSE GUTHRIE, FEDERICA MARINO-FR ANCIS, \\ CHARLOTTE BUSBY, JULIE MORRIS, EVE RUSSELL, FRANK MARGISON, \\ SEAN LENNON and JANE BYRNE
}

\begin{abstract}
Background Although there is good evidence that interventions for carers of people with Alzheimer's disease can reduce stress, no systematic studies have investigated psychotherapeutic intervention for patients themselves. This may be important in the earlier stages of Alzheimer's disease, where insight is often preserved.
\end{abstract}

\begin{abstract}
Aims The aim was to assess, in a randomised controlled trial, whether psychotherapeutic intervention could benefit cognitive function, affective symptoms and global well-being.
\end{abstract}

Method Individuals were randomised to receive six sessions of psychodynamic interpersonal therapy or treatment as usual; cognitive function, activities of daily living, a global measure of change, and carer stress and coping were assessed prior to and after the intervention.

Results No improvement was found on the majority of outcome measures. There was a suggestion that therapy had improved the carers' reactions to some of the symptoms.

\section{Conclusions There is no evidence to} support the widespread introduction of brief psychotherapeutic approaches for those with Alzheimer's disease. However the technique was acceptable and helpful individually.

Declaration of interest None.
Alzheimer's disease is devastating in terms of suffering of affected individuals, stress on carers and cost to society. Medication can effect symptomatic improvement (Burns et al, 1999) and psychological support can reduce strain in carers (Mittelman et al, 1996; Donaldson et al, 1997). Cognitivebehavioural therapy for carers can reduce carer stress and burden, and behavioural disturbance in affected individuals (Marriott et al, 2000). However, no studies have investigated psychotherapeutic intervention directed at those with Alzheimer's disease. In the early stages of disease, psychotherapeutic interventions may be beneficial as insight is often preserved and psychological adjustment is difficult for those who may assume they face a future of inevitable decline. Denial, as a defence mechanism, is common for those affected and their relatives (Bahro et al, 1997). Individual psychodynamic therapy has been described (Bahro et al, 1997) but there is no systematic research (Cheston, 1998). Some related 'emotion-oriented' therapies, including validation and reminiscence, have been promising (Woods, 2002). A Cochrane review of non-drug therapies found a benefit only for reality orientation (Koger et al, 1999; Neal \& Briggs, 2000; Spector et al, 2004).

The aim of this study was to assess, in a randomised controlled trial, whether a psychotherapeutic approach directed towards individuals with Alzheimer's disease could benefit cognitive function, affective symptoms and global well-being.

\section{METHOD}

\section{Design}

The study was a randomised controlled trial of psychodynamic interpersonal therapy compared with standard treatment in people with Alzheimer's disease. Independent assessments were carried out at baseline, and after 6 weeks and 3 months
(Fig. 1). The study was approved by the local research ethics committees.

\section{Procedure}

Individuals and their carers were recruited from referrals to the memory clinic in South Manchester, UK. The inclusion criteria were: a diagnosis of Alzheimer's disease according to NINCDS-ADRDA criteria (McKhann et al, 1984); a clinical dementia rating of 1 (Morris, 1993), indicating mild dementia; a score of 15 or above on the Mini-Mental State Examination (Folstein et al, 1975); living in their own home with a carer in regular contact; and the ability to communicate verbally.

Following consent, individuals were allocated to one of two groups - treatment or control-using computer-generated random numbers organised independently by the Department of Medical Statistics in South Manchester. Those allocated to the control group could elect to have the therapeutic sessions after the study. All assessments and therapeutic interventions were conducted in the individuals' own homes. Those taking anticholinesterase drugs for the treatment of Alzheimer's disease or other psychotropic medication (such as antidepressants) had to be clinically stable on these medications for at least 2 months prior to study entry.

\section{Therapeutic interventions}

Those in the treatment group received six sessions of psychodynamic interpersonal therapy with an experienced psychotherapist. Those in the control group received standard care, which consisted of general advice regarding the diagnosis and treatment of dementia, with out-patient review.

\section{Psychodynamic interpersonal therapy}

Psychodynamic interpersonal therapy was formerly known as the conversational model of psychotherapy (Hobson, 1985) and has been used to treat a wide variety of disorders including depression (Shapiro \& Firth, 1987; Shapiro et al, 1993), somatisation (Guthrie et al, 1991; Hamilton et $a l, 2000$ ) and self-harm (Guthrie et al, 2001). The principal aim of the therapy (in its brief format) is the identification of interpersonal conflicts or difficulties, which are causing or helping to maintain emotional distress. Client and therapist 


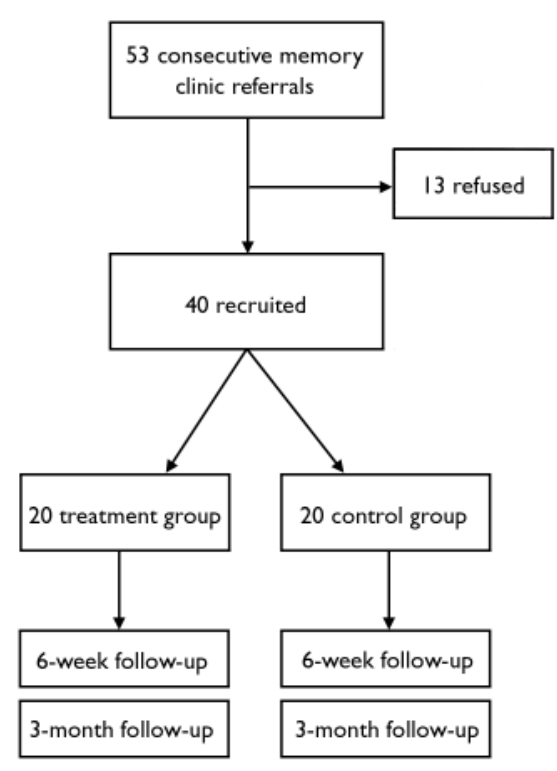

Fig. I Design of the trial of brief psychotherapy in Alzheimer's disease.

work together to find and test solutions to these problems, and both intrapsychic and practical changes are encouraged.

\section{Adaptation of the technique}

The therapy was adapted for people with Alzheimer's disease. Full details are available elsewhere (Brierley et al, 2003). The main adaptations included delivery in the individual's home and involving the carer in the treatment. Four specific psychological areas were targeted. Autobiographical narrative was used to strengthen self-worth. Important past conflicts, which resonated with current difficulties, were explored and resolved. The illness itself was discussed and emphasis placed on improving social and interpersonal relationships including, but not emphasising, the role of the partner. In addition to the individual therapy, the therapist spent $10 \mathrm{~min}$ each session with the carer, listening to the carer's needs and informing the carer of therapeutic progress.

\section{Implementation of the technique}

Psychotherapy sessions lasted $50 \mathrm{~min}$. The psychotherapy has been summarised in a manual (Shapiro \& Firth, 1987) and treatment fidelity was ensured by regular supervision using audiotapes. One session from each individual therapy was rated for adherence to the model using the Sheffield Psychotherapy Rating Scale (Shapiro \& Startup, 1993). This scale allows sessions to be rated according to three main subscales: one for psychodynamic interpersonal therapy; one for cognitive-behavioural therapy; and one for generic aspects of psychotherapy. The intervention showed high scores on the psychodynamic interpersonal therapy and generic subscales and low scores on the cognitivebehavioural therapy scale, confirming adherence to the model.

\section{Assessments of patients}

The following assessments were carried out before the start of the therapy, at the end of the therapy ( 6 weeks after recruitment) and at 3 months follow-up.

\section{Cornell Scale for Depression in Dementia}

This is a 19-item scale assessing depressive symptoms in people with dementia (Alexopoulos et al, 1988). It is rated on a threepoint scale of absent, mild or intermittent, and severe. A score of 8 or above is indicative of significant depressive symptoms.

\section{Mini-Mental State Examination}

This is a 30 -item measure of cognitive function, with a maximum score of 30 points (Folstein et al, 1975). It normally takes 5-10 min to complete.

\section{Revised Memory and Behavior Problems Checklist}

This is a 24-item questionnaire rating both the frequency of behavioural problems in those with dementia and the intensity of the reactions in their carers (Teri et al, 1992). Frequency and reaction are both rated on a six-point scale.

\section{Bristol Activities of Daily Living Scale}

This is a 20 -item questionnaire, rated by the carer in 10-15 min (Bucks et al, 1996). Twenty areas of daily activities are each rated on a five-point scale from no problem to severe problems.

\section{Assessments of carers \\ General Health Questionnaire}

This is a 12 -item self-report questionnaire to assess psychological distress and psychiatric morbidity (Goldberg \& Williams, 1985). It is completed in $5 \mathrm{~min}$ or less and each item is rated on a fourpoint scale.

\section{Beck Depression Inventory}

This is a 21-item self-report questionnaire to assess depression in the respondent (Beck et al, 1961). It normally takes $10-20 \mathrm{~min}$ to complete. Each item is scored from 0 to 3 and a total score is derived. A total score of 12 or more suggests the presence of depression.

\section{Ways of Coping Checklist}

This is a 42-item self-report questionnaire to assess the carer's coping strategies (Vitaliano et al, 1985). It normally takes 15-20 min to complete and is rated on a four-point scale, from not applicable to very much used.

\section{Global assessment}

Clinician's Interview-Based Global Impression of Change

This is a seven-point scale used by the researcher and an external supervisor to detect change in the patients at 6-week and 3-month follow-up (Guy, 1976). The scale goes from very much improved to very much worse. The rating was completed following a discussion between the research assistant (F.M.-F.) and the senior clinician (A.B.), who was masked to group membership (treatment or control).

The 20 individuals who took part in the treatment arm of the study completed a satisfaction survey. Four statements were presented and the patients were asked to reply.

\section{Statistical analysis, randomisation and calculation of sample size}

All analyses used the intention-to-treat principle. The effect of intervention was assessed by comparing changes in mean scores over time on continuous variables using analyses of covariance, with baseline scores and age as covariants. Some scores required a natural logarithmic transformation prior to analysis to produce a satisfactory approximation to a normal distribution. For these scores, geometric means (detransformed log means) are presented rather than simple arithmetic means. Chi-squared tests, where appropriate, were performed on categorical measures.

There are no current data upon which to base a power calculation. In our previous study (Marriott et al, 2000), group sizes of 14 were sufficient to detect a statistically significant difference. Based on these data, we allowed for a withdrawal rate of $20 \%$, 
Table I Participants' characteristics and participant and carer assessments at baseline and 6-week and 3-month follow-up

\begin{tabular}{|c|c|c|}
\hline Characteristic & Treatment group & Control group \\
\hline n (male:female) & $20(10: 10)$ & $20(11: 9)$ \\
\hline Age, years: mean (range) & $73.9(62-88)$ & 77.7 (59-91) \\
\hline \multicolumn{3}{|c|}{ Relationship of carer to patient: $n(\%)$} \\
\hline Spouse & $16(80)$ & $14(70)$ \\
\hline Child & $3(15)$ & $5(25)$ \\
\hline Other & I (5) & I (5) \\
\hline \multicolumn{3}{|l|}{ Medication: $n$ (\%) } \\
\hline On antidepressants & $5(25)$ & $3(15)$ \\
\hline On donepezil & $7(35)$ & $8(40)$ \\
\hline On rivastigmine & $7(35)$ & $5(25)$ \\
\hline \multicolumn{3}{|l|}{ Participant assessments } \\
\hline \multicolumn{3}{|c|}{ Cornell Scale: mean (s.d.) } \\
\hline Baseline & $5.9(2.6)$ & $5.1(2.8)$ \\
\hline 6-week follow-up & $5.4(2.6)$ & $5.5(3.1)$ \\
\hline 3-month follow-up & $5.1(2.5)$ & $5.6(3.0)$ \\
\hline \multicolumn{3}{|c|}{ Mini-Mental State Examination: mean (s.d.) } \\
\hline Baseline & $24.4(4.4)$ & $21.5(3.6)$ \\
\hline 6-week follow-up & $23.8(4.1)$ & $21.8(3.9)$ \\
\hline 3-month follow-up & $23.4(4.4)$ & $20.7(5.1)$ \\
\hline \multicolumn{3}{|c|}{ Revised Memory and Behavior Problems Checklist - } \\
\hline \multicolumn{3}{|c|}{ Carer's reaction: geometric mean (range) } \\
\hline Baseline & $8.1(0-33)$ & $8.4(0-22)$ \\
\hline 6-week follow-up & $4.5(0-38)$ & $8.4(0-24)$ \\
\hline 3-month follow-up & $7.2(0-42)$ & $5.1(0-12)$ \\
\hline \multicolumn{3}{|c|}{ Bristol Activities of Daily Living Scale: mean (s.d.) } \\
\hline Baseline & $8.9(6.4)$ & I3.I (7.5) \\
\hline 6-week follow-up & $7.5(4.4)$ & $9.9(5.1)$ \\
\hline 3-month follow-up & $8.4(6.7)$ & II.5 (5.8) \\
\hline \multicolumn{3}{|l|}{ Carer assessments } \\
\hline \multicolumn{3}{|c|}{ General Health Questionnaire: mean (s.d.) } \\
\hline Baseline & II.8 (5.0) & $10.3(2.1)$ \\
\hline 6-week follow-up & $11.0(3.6)$ & $\mathrm{II} .0(5.7)$ \\
\hline 3-month follow-up & II.4 (5.I) & $10.2(5.8)$ \\
\hline \multicolumn{3}{|c|}{ Ways of Coping Checklist: geometric mean (Section 2, range) } \\
\hline Baseline & $3.4(0.18)$ & $6.6(1.18)$ \\
\hline 6-week follow-up & $4.0(0.18)$ & $5.3(1.18)$ \\
\hline 3-month follow-up & $2.0(0.12)$ & $4.7(1.18)^{\prime}$ \\
\hline \multicolumn{3}{|c|}{ Global assessment } \\
\hline \multicolumn{3}{|c|}{ Clinician's Interview-Based Global Impression of Change } \\
\hline \multicolumn{3}{|c|}{ (\% rated as worse) } \\
\hline 6-week follow-up & 20 & 20 \\
\hline 3-month follow-up & 10 & 25 \\
\hline
\end{tabular}

I. Using analysis of covariance with baseline scores as covariant, there was a significant improvement in the treatment group at 3 months $(F(I, 35)=5.0, P=0.032)$ on Section 2 .

and chose to recruit 20 individuals in each group. Part of the rationale for this pilot study was to obtain some normative data on which to calculate a sample size for a definitive study.

\section{RESULTS}

\section{Study groups}

Fifty-three consecutive referrals to the memory clinic in South Manchester who satisfied the inclusion criteria were approached to take part in the study; 13 refused, leaving 40 people to be enrolled. The most common reasons for refusal were: the potential upset the therapeutic sessions could cause and having already taken part in other research projects.

Table 1 describes the study groups and main results from the assessments. There were 20 people recruited to each group. Most commonly it was the spouse who cared for the patient; $25 \%$ of the treatment group and $15 \%$ of the control group were on antidepressants, and approximately two-thirds of each group were on one of the anticholinesterase drugs for Alzheimer's disease. All participants completed the study and follow-up.

There were no significant differences over the course of the study in the outcome measures for the patients, including ratings on the Cornell Scale, Mini-Mental State Examination and Activities of Daily Living Scale, or in the global rating for the outcome measures for the carers. There were no changes over the course of the study in the General Health Questionnaire or Beck Depression Inventory. There was a trend towards a slight improvement in the carer's reaction to behavioural problems. Section 2 of the Ways of Coping Checklist showed a significant decline $(P<0.05)$; this section rates the carer's interaction with other people as an aid to coping.

There was no difference in the ratings when the patients were divided into two groups by Mini-Mental State Examination score (above or below 24). However, there was some evidence that carers of those with less cognitive impairment (score above 24) benefited more from the treatment in that they blamed themselves less for the problems (section 3 of the Ways of Coping Checklist at 3 months, mean value 0.14 compared with $0.35, P=0.031$ ).

\section{Qualitative assessments}

Every participant agreed with the statement 'I was able to discuss my difficulties with my counsellor and became more clear about what they are'. Eighty-three per cent agreed with the following three statements: 'I find doing things I can do and not thinking too much about what I cannot do, helps me feel less frustrated'; 'Although it sometimes felt painful talking about my past, it felt good to get things off my chest, and I felt calm'; and 'I have been able to talk 
about some things that have been difficult to talk to anyone else about'.

Some of the positive comments from patients included:

(a) 'I was able to confide and talk easy in a friendly way.'

(b) 'She drew out some points which I never realised...'

(c) 'It was beneficial but I don't know why.'

(d) 'My counsellor allowed me to bring out some things which I would not have discussed with relatives or friends.'

Comments from the carers included:

(a) 'It provided me with the opportunity to discuss the problems attached to being a full-time carer for my husband.'

(b) 'It also made me feel less guilty about making time for myself and the home.'

(c) 'My husband said he enjoyed talking to her after she had gone, but then forgot afterwards that she would be coming again.'

(c) 'It was a chance to discuss openly my wife's problem.'

The 20 participants who received therapy were visited between 6 and 12 months after recruitment. A semi-structured openended interview was carried out. Five of the patients had some recollection of the sessions, and all five confirmed that they had found it helpful.

\section{DISCUSSION}

\section{Main findings}

This study shows that it is possible to adapt a model of psychotherapy for those with Alzheimer's disease. No improvement was found on the majority of outcome measures in participants and their carers. However, there was a suggestion that the therapy had improved the carers' ways of coping with some of the symptoms of the disease.

The therapist was clearly a major source of support for the carers and the patients.

\section{Rationale for the trial}

We chose to target an area that has received relatively little attention in Alzheimer's disease. Traditional therapies have tended to be pharmacological in nature, targeting either cognitive or non-cognitive symptoms (Tariot, 1999). Non-pharmacological interventions, aside from some behavioural techniques (Allen-Burge et al, 1999), have

\section{CLINICAL IMPLICATIONS}

Psychotherapeutic approaches can be adapted for people with dementia.

- Treatments directed at those with dementia can have positive effects on carers.

People with dementia can appreciate psychotherapeutic interventions.

\section{LLMITATIONS}

The sample size was small.

- The outcome measures chosen were probably not sensitive enough to measure marginal improvements.

The psychotherapeutic method had not previously been validated on older people.

ALISTAIR BURNS, MD, FRCP, FRCPsych, Department of Psychiatry, Wythenshawe Hospital, Manchester; ELSE GUTHRIE, MD, FRCPsych, Department of Psychiatry, Manchester Royal Infirmary, Manchester: FEDERICA MARINO-FRANCIS, CHARLOTTE BUSBY, MRCPsych, Department of Psychiatry, Wythenshawe Hospital, Manchester; JULIE MORRIS, MSc, Department of Medical Statistics, Wythenshawe Hospital, Manchester; EVE RUSSELL, MD, MRCPsych, FRANK MARGISON, FRCPsych, SEAN LENNON, FRCPsych, JANE BYRNE, FRCPsych, Department of Psychiatry, Wythenshawe Hospital, Manchester, UK

Correspondence: Professor Alistair Burns, Department of Psychiatry, 2nd Floor, Education and Research Centre,Wythenshawe Hospital, Southmoor Road, Manchester M23 9LT, UK. Tel: +44 (0)।6I 29I 5887; fax: +44 (0)I6I 29I 5882; e-mail: Alistair.Burns@manchester.ac.uk

(First received I5 June 2004, final revision 25 October 2004, accepted 5 November 2004)

concentrated on carers, and psychological approaches are of proven benefit in reducing carer strain (Marriott et al, 2000). As far as we are aware, this is the first randomised controlled trial of a psychotherapeutic intervention in people with Alzheimer's disease using standardised outcome measures. The psychotherapeutic approach was determined following a pilot study and adapted to the individual needs of the participants, as the model dictates. The joint sessions with the participants and carers merely helped the therapist to focus on those symptoms that were considered important and distressing.

\section{Reasons for non-response}

The finding that the intervention had no effect on measures that reflect the core features of the illness (cognitive function, activities of daily living) is not surprising. Only six sessions were provided which, in psychotherapeutic terms, is a low-dose treatment, and this may partly explain the lack of effect. In addition, a longer study would be needed to assess the more likely benefits in terms of stabilisation of disease. The beneficial effect on carers is indicated by the scores on the Ways of Coping Checklist, which showed that the therapy helped carers by providing someone to talk to and, for those caring for people with mild dementia, diminished the carers' sense of self-blame. There was minimal involvement of the carers in the therapy. A beneficial effect on patients themselves can be inferred from the improvement in the global rating of well-being.

It is not surprising that the involvement of the therapist appeared to have a positive impact and is in accordance with other experience in the field. What is important is that the therapy can be adapted for use in people with cognitive impairment.

The trend towards improvements in both carer and patient outcomes attests to the potential benefit of non-pharmacological interventions in this group. Future studies in this area should concentrate specifically on approaches that combine outcomes of carers and those in their care. The interdependency of the aspirations and outcomes of people with Alzheimer's 
disease and their carers is emphasised by this project and will influence future studies in this area.

\section{ACKNOWLEDGEMENTS}

The study was carried out in South Manchester Hospitals NHS Trust and was funded by a generous donation from the Sir Halley Stewart Trust. We thank all the participants and their carers.

\section{REFERENCES}

Alexopoulos, G. S., Abrams, R. C., Young, R. C., et al (1988) Cornell Scale for Depression in Dementia. Biological Psychiatry, 23, 27I-284.

Allen-Burge, R., Stevens, A. B., Burgio, L. D. (1999) Effective behavioral interventions for decreasing dementia-related challenging behavior in nursing homes. International Journal of Geriatric Psychiatry, 14, 213-228.

Bahro, M., Silber, E. \& Sunderland, T. (1997)

Psychodynamic treatment in Alzheimer's disease. Revue Medicale de la Suisse Romande, II7, 659-66I.

Beck, A. T., Ward, C. H., Mendelson, M., et al (196I) An inventory for measuring depression. Archives of General Psychiatry, 4, 56I-57I.

Brierley, E., Guthrie, E., Busby, C., et al (2003)

Psychodynamic interpersonal therapy for early Alzheimer's disease. British Journal of Psychotherapy, 19, 435-446.

Bucks, R. S., Ashworth, D. L., Wilcock, G. K., et al (1996) Assessment of activities of daily living in dementia: development of the Bristol Activities of Daily Living Scale. Age and Ageing, 25, I13-120.

Burns, A., Rossor, M., Hecker, J., et al (1999) The effects of donepezil in Alzheimer's disease - results from a multinational trial. Dementia and Geriatric Cognitive Disorders, 10, 237-244.
Cheston, R. (1998) Psychotherapeutic work with people with dementia: a review of the literature. British Journal of Medical Psychology, 71, 2II-23I.

Donaldson, C., Tarrier, N. \& Burns, A. (1997) The impact of the symptoms of dementia on caregivers. British Journal of Psychiatry, 170, 62-68.

Folstein, M. F., Folstein, S. E. \& McHugh, P. R. (1975) "Mini-Mental State": a practical method for grading the cognitive state of patients for the clinician. Journal of Psychiatric Research, 12, 189-198.

Goldberg, D. P. \& Williams, P. (1985) A User's Guide to the General Health Questionnaire. Windsor: NFERNelson.

Guthrie, E., Creed, F., Dawson, D., et al (1991) A controlled trial of psychological treatment for the irritable bowel syndrome. Gastroenteroloy, 100, 450-457.

Guthrie, E., Kapur, N., Mackway-Jones, K., et al (200I) A randomised controlled trial of brief psychological intervention after deliberate self poisoning. BMJ, 323, 135-138.

Guy, w. (1976) Clinical global impressions. In ECDEU Assessment Manual for Psychopharmacology. Rockville, MD: National Institute of Mental Health.

Hamilton, J., Guthrie, E., Creed, F., et al (2000) A randomised controlled trial of psychotherapy in patients with chronic functional dyspepsia. Gastroenterology, II9, 661-669.

Hobson, R. F. (1985) Forms of Feeling: The Heart of Psychotherapy. London: Tavistock Publications.

Koger, S. M., Chapin, K. \& Brotons, M. (1999) Is musi therapy an effective intervention for dementia? A metaanalytic review of literature. Journal of Music Therapy, 36 $2-15$

Marriott, A., Donaldson, C., Tarrier, N., et al (2000) Effectiveness of cognitive-behavioural family intervention in reducing the burden of care in carers of patients with Alzheimer's disease. British Journal of Psychiatry, 176, 557-562.
McKhann, G., Drachman, D., Folstein, M., et al (1984) Clinical diagnosis of Alzheimer's disease: report of the NINCDS-ADRDA Work Group under the auspices of Department of Health and Human Services Task Force on Alzheimer's Disease. Neurology, 34 939-944.

Mittelman, M. S., Ferris, S. H., Shulman, E., et al (1996) A family intervention to delay nursing home placement of patients with Alzheimer's disease. A randomized controlled trial. JAMA, 276, 1725-1731.

Morris, J. C. (1993) The Clinical Dementia Rating (CDR): current version and scoring rules. Neurology, $\mathbf{4 3}$ 24I2-24I4.

Neal, M. \& Briggs, M. (2000) Validation therapy for dementia. Cochrane Database Systematic Review, issue 2 (CD001394)

Shapiro, D. \& Firth, J. (1987) Prescriptive

exploratory psychotherapy. Outcomes of the Sheffield Psychotherapy Project. British Journal of Psychiatry, I5I 790-799.

Shapiro, D. A. \& Startup, M. (1993) Measuring therapist adherence in exploratory therapy. Journal of Psychotherapy Practice and Research, 2, 193-203.

Spector, A., Orrell, M., Davies, S., et al (2004)

Reminiscence therapy for dementia (Cochrane Review) Cochrane Library, issue 2. Chichester: John Wiley \& Sons.

Tariot, P. N. (1999) Treatment of agitation in dementia. Journal of Clinical Psychiatry, 60, II-20.

Teri, L., Truax, P., Logsdon, R., et al (1992)

Assessment of behavioural problems in dementia: the Revised Memory and Behavior Problems Checklist. Psychology and Aging, 4, 622-631.

Vitaliano, P. P., Russo, J., Carr, J. E., et al (1985) The Ways of Coping Checklist: Revision and psychometric properties. Multivariate Behavioral Research, 20, 3-26.

Woods, R.T. (2002) Non-pharmacological techniques. In Evidence-Based Dementia Practice (eds N. Qizilbash, H. Schneider, P. Brodaty, et al), pp. 428-446. Oxford: Blackwell. 